measurements of $p$ and $P^{\prime}$ for two wireless frequencies $f_{1}$ and $f_{2}$, we have from (1):

$f_{1} \log p_{1}-f_{2} \log p_{2}=\frac{\nu}{2 c}\left[f_{2}\left(P_{2}^{\prime}-P_{2}\right)-f_{1}\left(P^{\prime}{ }_{1}-P_{1}\right)\right]$.

Also we have, generally,

$$
P_{2} f_{2}-P_{1} f_{1}=\int_{f_{1}}^{f_{2}} P^{\prime} d f ; \ldots \ldots .
$$

so that, with a little reduction, there is obtained

$$
\frac{\nu}{2 c}=\frac{f_{1} \log p_{1}-f_{2} \log p_{2}}{\text { area } X}, \ldots \ldots
$$

where the area $X$ is shown in Fig. 1 on the usual $\left(P^{\prime}, f\right)$ diagram. From $(4)$

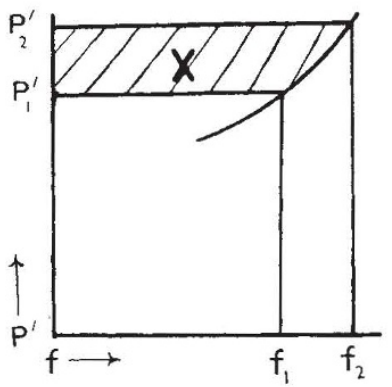

Fig. 1.

$\nu$ can be calculated. In differential notation (4) may also be written

$$
\frac{\nu}{2 c}=-\frac{1}{f} \frac{\delta(f \log \rho)}{\delta P^{\prime}} \ldots \ldots \ldots
$$

A further point of interest is that when $v$ has been found in this way, the value of $P$, the optical path, may be estimated for any frequency with the aid of (1).

Halley Stewart Laboratory,

E. V. Appleton.

30 Chesterford Gardens,

Hampstead, N.W.3.

April 4.

${ }^{1}$ NatURe, 135, 435, March 16, 1935.

\section{Ramsay and Helium}

A sToRy is current in scientific circles which relates to the discovery of helium. It is said that after listening to the lecture on the discovery of argon at the meeting of the Royal Society on January 31, 1895, Mr. H. A. Miers (Sir Henry Miers) wrote to Ramsay, directing his attention to Hillebrand's discovery that minerals of the uraninite group gave off nitrogen, when heated with acids. The story continues to the effect that Ramsay, being a very energetic man, at once went out and bought up all the clévite that was available, treated the mineral with acid, and got off a gas which proved to be helium. The story is told without malice, and, no doubt, would have amused Ramsay, but, unfortunately, it is true neither of the man nor of the period. The true story is characteristic of both.

Ramsay certainly received the letter from Mr. Miers on Friday, February 1, but as he writes in his notebook, he spent that day, and also the following
Saturday and Sunday, in revising and typing the paper for the Royal Society. The next note in the notebook is: "Didn't do much till Friday 15th", when he made and fitted up his first Töpler pump. Actually he had a lot of time to put in at the College, making up arrears of teaching work. Then he carried out some additional determinations on the density of argon, purifying the gas specially for the purpose, the results appearing as an addendum to the argon paper. This completed one piece of work.

Ramsay next turned his attention to some experiments on the direct determination of the specific heat of argon, designed to answer criticisms put forward in the discussion at the Royal Society on January 31. The apparatus was made in the first week in March, and the first experiment was carried out on March 9. About this time his assistant, Mr. Donald Matthews, carried out the first experiment on clévite. Ramsay noted on March 20: "Matthews had obtained from clévite, about a gram of which I bought from Gregory (88, Fitsroy Square) for $3 / 6$, a quantity of gas by boiling with dilute sulphuric acid". However, this work had been completed during the previous week, for there is a note, later : "Crookes got the first lot (Saturday, March 16) but was too busy to examine it all the week". A preliminary examination had, however, been made, for on March 17 Ramsay had written to his friend, Mr. Buchanan: "Crookes thinks that the spectrum is new, and I don't see how it can be anything old, except argon, and that it certainly is not. We are making some more of it, and in a few days I hope that we shall have enough of it to do a density." The original $3 s .6 d$. worth of clévite had been used up, and a further quantity was purchased.

In the meantime, Ramsay continued the experiments on the specific heat of argon, but as no communication was received from Crookes, on the morning of Saturday, March 23, he borrowed a second induction coil and proceeded to compare the spectrum of the new gas, 'crypton', with that of argon." "While observing Crookes telegraphed-Crypton is helium, 58749. Come and see it. Went and saw it"-so runs the record.

The current story does not accord with the spirit of the man, who could work with amazing rapidity, but who would settle one problem to his own satisfaction before proceeding to the next. Nor is it in accord with the spirit of an age, in which the scramble for priority was rather less obvious than at present.

A note on the discovery was written the same afternoon and communicated to the meeting of the Royal Society on the following Thursday. In those days the Royal Society assumed that the news of a discovery by one of its fellows should first be announced at one of its meetings, if the Society were in session; and in the year 1898 the fact that the discovery of krypton had been communicated simultaneously to the Royal Society and to the Paris Academy, and had become public through the latter body, evoked indignant comments at the meeting at which our paper was read. By relinquishing its prerogative the Society has lost a good deal.

In a dramatised version of the discovery of helium the departure from fact might be justified, but as a matter of mere history the true story is possibly the more interesting.

Department of Chemistry,

M. W. Travers.

University of Bristol. March 15. 